\title{
KESEJAHTERAANSPIRITUAL DAN DEPRESI PADA KELUARGA PASIEN YANG DIRAWAT DI RUANG ICU RSUD BANYUMAS
}

\author{
Agus Subarkah $^{1}$, Nur Isnaini \\ Fakultas Ilmu Kesehatan Program Studi Sarjana Keperawatan Universitas \\ Muhammadiyah Purwokerto \\ Jl. Raya Dukuh Waluh, PO BOX 202, Purwokerto 53182, Kembaran Banyumas, Indonesia \\ subarkaha126@gmail.com
}

\begin{abstract}
Abstrak
Intensive Care Unit (ICU) merupakan salah satu ruang rawat inap untuk melakukan observasi, perawatan dan terapi pasien yang terancam jiwanya akibat kegagalan fungsi organ. Perubah an yang terjadi pada pasien dapat menimbulkan tekanan dan menjadi beban tersendiri bagi keluarga sebagai care giver dan dapat berdampak pada psikologis keluarga seperti depresi. Tujuan adalah mengetahui hubungan antara kesejahteraan spiritual dengan depresi pada keluarga pasien yang dirawat di ruang ICU RSUD Banyumas. Penelitian ini merupakan penelitian korelasi dengan desain cross sectional. Sampel dalam penelitian ini adalah keluarga pasien yang dirawat di ICU RSUD Banyumas sebanyak 32 responden dengan teknik purposive sampling. Analisa dalam penelitian ini menggunakan uji korelasi pearson. Hasil penelitian menunjukan tidak terdapat hubungan antara kesejahteraan spiritual dengan depresi pada keluarga pasien yang dirawat di ruang ICU RSUD Banyumas ( $p$ value 0,088 < $0,05)$. Semakin baik kesejahteraan spiritual keluarga pasien maka semakin berk urang resiko untuk mengalami depresi saat pasien dirawat di ruang ICU.
\end{abstract}

Kata Kunci : Kesejahteraan spiritual, depresi, ICU

\begin{abstract}
The Intensive Care Unit (ICU) is one of the inpatient rooms in a hospital the purpose of observing, treating and treating patients who are in danger of life due to organ failure. Chang es that occur in patients can cause pressure and become a burden for the family as caregivers and can have an impact on family psychology such as depression. The purpose of this study was to determine the relation ship between spiritual well-being and depression in the families of patients who were treated in the ICU Banyumas Hospital. This study is a correlation study with a cross sectional design. The sample in this study were the families of patients who were treated at the ICU at Banyumas Hospital as many as 32 respondents with purposive sampling technique. The analysis in this study used the Pearson correlation test. The results showed that there was no relationship between spiritual well-being and depression in the families of patients treated in the ICU room at Banyumas Hospital ( $p$ value $0.088<$ 0.05). The better the spiritual welfare of the patient's family, the less the risk of experiencing depression when the patient is admitted to the ICU.
\end{abstract}

Keywords: spiritual well-being, depression, ICU

\section{PENDAHULUAN}

ICU merupakan ruang rawat inap di rumah sakit memiliki staf dan perlengkapan khusus untuk ditujukan untuk observasi, perawatan dan terapi pasien yang terancam jiwanya akibat kegagalan fungsi organ tubuh baik akibat penyakit, trauma atau komplikasi (Kemenkes RI, 2010). Pasien yang dirawat di ruang ICU dalam keadaan kritis, kehilangan kesadaran, atau kegagalan fungsi vital sehingga perlu pamantauan hemodinamik yang terus menerus selama 24 jam dan penggunaan peralatan penunjang yang memadai untuk mendapatkan hasil yang optimal (Kiptiyah, 2013). Perubahan yang terjadi harus dianalisis secara tepat agar mendapatkan perawatan atau pengobatan yang tepat. Tugas perawat untuk

Corresponding author:

Agus Subarkah

subarkaha126@gmail.com 
memberikan asuhan keperawatan secara holistik perlu melibatkan keluarga sebagai care giver.

Davidson et al (2012) juga menjelaskan bahwa care giver merupakan orang yang memberikan perawatan secara fisik, psikologis dan emosional bagi individu yang menderita penyakit atau kecacatan, biasanya individu merupakan seseorang yang dicintai. Salah satu stressor yang mempengaruhi kondisi psikologis keluarga adalah lama pasien dirawat yaitu lebih dari 5 hari dan tingkat keseriusan penyakit pasien (Saragih, 2017). Kasus post laparatomi merupakan salah satu kasus terbanyak di ICU RSUD Banyumas. Sebagian besar pasien tersebut terpasang endotracheal tube (ETT) dan pernafasan dibantu dengan ventilasi mek anik (Rekam Medis RSUD Banyumas, 2019). Hal tersebut dapat menimbulkan tekanan dan menjadi beban tersendiri bagi keluarga sebagai care giver dan dapat berdampak pada psikologis keluarga. Keluarga pasien yang sakit kritis biasanya mengalami tekanan psikologis seperti kecemasan, stress dan depresi (Fumis, Ranzani, Martins \& Schettino, 2015).

Depresi merupakan gejala psikotik bila keluhan yang bersangkutan tidak sesuai lagi dengan realitas, tidak dapat menilai realitas dan tidak dapat dimengerti oleh orang lain. Gangguan depresi ini terjadi akibat adanya suatu kesedihan yang sangat mendalam. Perasaan tersebut muncul karena kecewa mengalami situasi yang sama sekali tak terduga dan tak diharapkan terjadi dalam hidupnya (Yosep, 2014).

Kejadian depresi pada keluarga yang merawat pasien dengan penyakit kronik atau kritis di rumah sakit cukup tinggi. A'la (2015) menjelaskan dalam penelitiannya bahwa tingkat depresi keluarga yang meraat pasien stroke di RSD Soebandi Jember dalam kategori tinggi dengan rerata skor 55.79. Sedangkan Suprihatiningsih (2019) dalam penelitiannya menjelaskan bahwa depresi keluarga yang merawat pasien kanker yang menjalani kemoterapi di RSUD Prof Dr Margono cukup tinggi dengan rerata skor 26.23 .

Ketika depresi muncul, spiritual seseorang akan terganggu akibat pemaknaan terhadap diri, orang lain dan Tuhan berubah. Ketidakterimaan terhadap keadaan juga akan memicu terganggunya hubungan antar sesama dan hubungan dengan Tuhan, sehingga aspek religiusitas akan terganggu (Fisher, 2009). A'la
(2015) menjelaskan dalam penelitiannya bahwa terdapat hubungan bermakna antara kesejahteraan spiritual dan depresi pada keluarga pasien stroke $(\mathrm{p}=0.000)$. Selain itu Ando (2010) juga menjelaskan bahwa terd apat hubungan antara kesejahteraan spiritual (spiritual well being) dengan kejadian depresi keluarga pasien kanker di rumah paliatif Jepang.

Kesejahteraan spiritual merupakan rasa keharmonisan, saling kedekatan antara diri dengan oran lain, alam dan kepada Tuhan (Yusuf, 2016). Hasil penelitian Aflah (2017) menjelaskan bahwa sebagian besar keluarga pasien yang dirawat di ICU RSUD dr Loekmono Hadi Kudus memiliki tingkat spiritualitas tinggi $(90.6 \%)$.

Hasil studi pendahuluan dengan melakukan wawancara pada 10 keluarga pasien yang dirawat di ICU RSUD Banyumas pada 12 Juli 2019 didapatkan 7 keluarga mengatakan merasa sedih, takut kehilangan pasien dan terkadang mengadu kepada Tuhan mengapa memberikan cobaan yang berat kepada keluarganya. Sedangkan 3 keluarga mengatakan ikhlas dengan kondisi pasien saat ini dan selalu berharap atas kesembuhan keluarganya. Sedangkan hasil studi pendahuluan dengan pengisian kuesioner Beck's Depression Inventory dan Spiritual Well Being Scale pada 5 orang keluarga pasien yang merawat pasien di ICU diperoleh 4 orang memiliki kategori depresi sedang, 1 orang depresi ringan 3 orang memiliki tingkat spiritual kurang baik dan 2 orang memiliki tingkat spiritual baik. Melihat data dan fakta diatas peneliti ingin meneliti hubungan antara kesejateraan spiritual dengan depresi pada keluarga pasien yang dirawat di ruang ICU RSUD Banyumas

\section{METODE PENELITIAN}

Desain penelitian menggunakan korelasi dan pendekatan cross sectional. Populasi adalah semua keluarga pasien yang dirawat di ruang ICU RSUD Banyumas sebanyak 35 orang. Jumlah sampel penelitian sejumlah 32 orang dengan teknik purposive sampling. Adapun kriteria sampel dalam penelitian ini adalah sebagai berikut, 1) kriteria inklusi; a) Keluarga pasien yang dirawat di ruang ICU RSUD Banyumasminimal 24 jam; b) Keluarga adalah orang terdekat yang merawat pasien yaitu suami/istri pasien, anak kandung pasien atau orangtua pasien; c) Dapat 
membaca dan menulis; d) Bersedia menjadi responden; e) Usia diatas 20 tahun; f) Beragama Islam; g) Pendidikan minimal Sekolah Dasar (SD); h) Minimal memiliki tingkat pendapatan rendah. 2) Kriteria eksklusi; a) Tidak bersedia menjadi responden dan b) Keluarga pasien yang dirawat di ICU RSUD Banyumas kurang dari 24 jam.

Pengumpulan data dengan kuesioner, kesejahteraan dengan Spiritual Well Being Scale (SWBS) dan Beck's Depression Inventory (BDI). Sebelum dilakukan analisis peneliti melakukan uji normalitas variabel depresi menggunakan Shapiro-Wilk data tidak berdistribusi normal, $p<0,001$. Sedangkan uji normalitas variabel kesejahteraan spiritual menunjukkan data berdistribusi normal, $p=$ 0,395 . Oleh karena uji statistik penelitian ini menggunakan uji korelasi pearson.

\section{HASIL}

Tabel 1

Karakteristik Keluarga

\begin{tabular}{|c|c|c|}
\hline Karakteristik & Jumlah & $\%$ \\
\hline \multicolumn{3}{|l|}{ Umur } \\
\hline 1. $0-11$ tahun & 0 & 0 \\
\hline 2. $12-25$ tahun & 2 & 6,3 \\
\hline 3. 26- 45 tahun & 18 & 56,3 \\
\hline 4. $\geq 46$ tahun & 12 & 37,5 \\
\hline \multicolumn{3}{|l|}{ Hubungan Dengan Pasien } \\
\hline 1. Orang Tua & 3 & 9,4 \\
\hline 2. Suami & 8 & 25,0 \\
\hline 3. Istri & 5 & 15,6 \\
\hline 4. Anak & 15 & 46,9 \\
\hline 5. Nenek/Kakek & 1 & 3,1 \\
\hline \multicolumn{3}{|l|}{ Agama } \\
\hline 1. Islam & 32 & 100 \\
\hline 2. Non Islam & 0 & 0 \\
\hline \multicolumn{3}{|l|}{ Jenis Kelamin } \\
\hline 1. Laki-laki & 15 & 46,9 \\
\hline 2. Perempuan & 17 & 53,1 \\
\hline \multicolumn{3}{|l|}{ Pendidikan } \\
\hline 1. $\mathrm{SD}$ & 14 & 43,8 \\
\hline 2. SMP & 8 & 25,0 \\
\hline 3. SMA & 9 & 28,1 \\
\hline 4. Diploma & 1 & 3,1 \\
\hline 5. Sarjana & 0 & 0 \\
\hline \multicolumn{3}{|l|}{ Penghasilan } \\
\hline $1 .<1.500 .000$ & 21 & 65,6 \\
\hline 2. $1.500 .000-2.500 .000$ & 8 & 25,0 \\
\hline 3. $2.500 .000-3.500 .000$ & 2 & 6,3 \\
\hline 4. $>3.500 .000$ & 1 & 3,1 \\
\hline \multicolumn{3}{|l|}{ Sumber Pembiaya an } \\
\hline 1. BPJS & 32 & 100 \\
\hline 2. Mandiri & 0 & 0 \\
\hline
\end{tabular}

\begin{tabular}{lrr}
\hline Pekerjaan & & \\
1. Wira swasta & 4 & 12,5 \\
2. PNS & 1 & 3,1 \\
3. Swasta & 5 & 15,6 \\
4. IRT & 15 & 46,9 \\
5. Buruh & 7 & 21,9 \\
\hline Jumlah & 32 & 100 \\
\hline
\end{tabular}

Sumber : Data Primer diolah, 2019

Karakteristik keluarga sebagian besar berumur 26-45 tahun (56,3\%), memiliki hubungan dengan pasien sebagai anak $(46,9 \%)$, beragama Islam $(100 \%)$, berjenis kelamin perempuan $(53,1 \%)$, berpendidikan SD $(43,8 \%)$, berpenghasilan $<1.500 .000(65,6 \%)$, sumber pembiayaan dari BPJS $(100 \%)$ dan bekerja sebagai Ibu Rumah Tangga (46,9\%).

Tabel 2

Disktribusi Frekuensi Tingkat Depresi Keluarga

\begin{tabular}{|c|c|c|c|}
\hline No & Depresi & Frekuensi & $\%$ \\
\hline \multirow[t]{2}{*}{1.} & Depresi & 22 & 68,8 \\
\hline & Ringan & & \\
\hline 2. & $\begin{array}{l}\text { Depresi } \\
\text { Sedang }\end{array}$ & 6 & 18,7 \\
\hline \multirow[t]{2}{*}{3.} & Depresi Berat & 4 & 12,5 \\
\hline & Jumlah & 32 & 100,0 \\
\hline
\end{tabular}
responden adalah ringan $(62,5 \%)$ dan memiliki tingkat kesejahteraan spiritual baik $(56,3 \%)$.

Tabel 3

Disktribusi Frekuensi Kesejahteraan Spiritual Keluarga Pasien

\begin{tabular}{llcc}
\hline No & $\begin{array}{l}\text { Kesejahteraan } \\
\text { Spiritual }\end{array}$ & Frekuensi & \% \\
\hline 1. & $\begin{array}{l}\text { Kesejahteraan } \\
\text { spiritual kurang }\end{array}$ & 14 & 43,8 \\
2. & $\begin{array}{l}\text { Kesejahteraan } \\
\text { spiritual baik }\end{array}$ & 18 & 56,3 \\
\hline & Jumlah & 32 & 100,0 \\
\hline
\end{tabular}

Sumber : Data Primer diolah, 2019

Tabel 4

Korelasi Pearson Antara Kesejahteraan Spiritual Dengan Depresi

\begin{tabular}{lll}
\hline \multirow{2}{*}{ Vaiabel } & \multicolumn{2}{c}{ Depresi } \\
\cline { 2 - 3 } & $R_{s}$ & $p$ \\
\hline$-0,306$ & 0,088 \\
\hline
\end{tabular}

Sumber : Data Primer diolah, 2019

Hasil uji korelasi pearson diperoleh $p$ 0.088 , artinya tidak ada hubungan kesejahteraan spiritual dengan depresi pada keluarga pasien yang dirawat di ICU RSUD Banyumas. 


\section{PEMBAHASAN}

Tingkat depresi ringan $(68,8 \%)$ dan sebagian kecil memiliki tingkat depresi berat $(12,5 \%)$. Hasil ini berbeda dengan penelitian A'la (2015) tentang depresi dan kesejahteraan spiritual keluarga pasien stroke yang menjelaskan bahwa sebagan besar respon den memiliki tingkat depresi tinggi dengan rata-rata skor depresi 55,79.

Hal ini kemungkinan disebabkan karena lamanya merawat pasien sebagaimana dinyatakan oleh Suprihatiningsih (2019) y ang menjelaskan bahwa depresi merupakan kontribusi dari lamanya merawat pasien, lamanya waktu penanganan dan perawatan berulang pada pasien. Hasil penelitan menunjukan bahwa sebagian besar keluarga menemani pasien yang dirawat selama 2 hari $(56,3 \%)$. Hal ini terjadi karena proses a daptasi pada kebosanan mendampingi pengobatan, kesedihan, kecemasan serta melihat efek samping yang timbul mempengaruhi tingkat gejala depresi (Networks, 2006). Pada umumnya, tingkat depresi akan lebih rendah ketika merawat pasien yang sudah semakin lama dirawat (Suprihatiningsih, 2019).

Tingkat kesejahteraan spiritual responden sebagian besar dalam kategori baik $(56,3 \%)$. Sejalan dengan penelitian Mirwanti R dan Nuraeni A (2016) menunjukkan tingkat kesejahteraan spiritual didominasi kategori baik (35\%). Hal ini dapat disebabkan karena latar belakang agama yang sama yaitu Islam.

Sejalan dengan penelitian Asmadi (2008) yang menyatakan bahwa kesejahteraan spiritual dapat disebabkan oleh Agama. Agama sebagai aspek penting spiritual sangat mempengaruhi spiritual. Pada umumnya individu selalu memposisikan keyakinan y ang ada dalam dirinya merupakan bagian yang terpenting dalam kehidupan moralnya (Suprihatiningsih, 2019).

Hasil analisis data menggunakan uji korelasi pearson diperoleh hasil tidak terdapat hubungan kesejahteraan spiritual dengan depresi pada keluarga pasien yang dirawat $p$ 0.088. Pendapat peneliti sesuai dengan hasil penelitian dilapangan bahwa sebagian besar keluarga merasa pasrah dan hanya bisa sabar dengan ketentuan yang sudah Tuhan berikan. Dalam penelitian ini kesejahteraan spiritual tidak terbukti berhubungan dengan adanya tingkat depresi pada penunggu pasien di ruang ICU RSUD Banyumas yang dimungkinkan karena bermacam faktor pendukung yang lain. Faktor pendukung lain bisa dikarenakan saat dilakukan perawatan pasien di ruang ICU, keluarga atau penunggu pasien sudah paham tentang kondisi dan tindakan perawatan yang akan dilakukan serta kemungkinan y ang ak an terjadi pada kondisi pasien tersebut.

Diketahuinya kondisi dan proses perawatan pasien selama di rawat di ruang ICU akan memperkecil pemicu terjadinya depresi yang berkelanjutan pada penunggu pasien, sehingga penunggu yang belum mempunyai kesejahteraan spiritual yang baikpun akan tetap merasa tenang selama proses mendampingi anggota keluarganya yang dirawat di ICU RSUD Banyumas. Meskipun dalam kondisi nyata penunggu yang mempunyai tingkat kesejahteraan spiritual tinggi akan lebih memahami dan menerima apapun keadaan pasien yang dirawat di ICU, dan berpendapat bahwa semua cobaan ini sudah digariskan oleh Tuhan.

Depresi menurut Pieter dan Lubis (2011) merupakan suatu gangguan alam perasaan ditandai adanya pasien merasa sedih yang dengan durasi cukup lama atau secara terus-menerus yang mengganggu kehidupan sosial maupun fisik yang menurun dan ketidakterimaan. Seorang pasien y ang merasa tidak terima akan penyaitnya atau keadaannya selama dirawat akan memicu marah dan kekecewaan pada Tuhan, sehingga aspek religiusitas turun dan bermasalah (Fisher, 2009). Pasien dengan kesejahteraan spiritual baik akan memiliki keharmonisan, kedek atan antara diri dengan oran lain, alam dan kepada Tuhan (Yusuf, 2016). Seseorang yang memiliki kesejahteraan spiritual yang baik cukup merasa bahagia dan bersyukur terhadap ketentuan Alloh, tidak mengeluh dan senantiasa mengingat Allah dalam berbagai kondisi (Nawawi, 2011).

\section{KESIMPULAN}

Hasil penelitian menunjukkan tidak ada hubungan kesejahteraan spiritual dengan depresi pada keluarga pasien yang dirawat di ICU.

Bagi peneliti selanjutnya disarankan untuk menambahkan variabel penelitian sehingga dapat dilakukan analisis multivariat dan mengontrol faktor yang mempengaruhi variabel penelitian. Diharapkan keluarga untuk selalu meningkatkan spiritualitasnya dengan 
cara mendekatkan diri kepada tuhan dan selalu berpikir positif dalam segala kejadian yang dialaminya dengan harapan mencegah terjadinya depresi selama masa perawatan pasien.

\section{DAFTAR PUSTAKA}

Aflah, A.N. (2017). Hubungan Spiritualitas Dengan Tiingkat Kecemasan Keluarga Pasien di Ruang ICU RSUD dr. Loekmono Hadi Kudus. Prosiding HEFA, 1(1)

A’la, M. Z., Komarudin, \& Efendi D. (2015). Kesejahteraan Spiritual keluarga pasien Stroke dan Kaitannya dengan Depresi. Jurnal Ners dan Kebidanan Indone sia. ISSN 23547642

Ando, M., Morita, T., Miyashita, M., Sanjo, M., Kira, H., dan Shima, Y. (2010). Effects of bereavement life review on spiritual well-being and depression. Journal of Pain and Symptom Management, 40 (3), 453-459.

doi:https://doi.org/10.1016/j.jpainsymma n.2009.12.028.

Asmadi, N. (2008). Konsep Dasar Keperawatan. Jakarta: EGC

Davidson, G. C., Neale, J. M., dan Kring, A. M. (2012). Psikologi Abnormal. Jakarta : PT Rajaggrafindo permai.

Fisher, J. (2009). Development and application of a spiritual well-being questionnaire called SHALOM. Religions, 1(1), 105121. doi:10.3390/rel1010105.

Fumis, Ranzani, Martins \& Schettino. (2015). Emotional disorder in pairs of patients and their family members during and after ICU stay. PLoS ONE, (1). 1-12. Doi : 10.1371/journal.pone.0115332

Kemenkes RI. (2010). Pedoman Penyelengraan Pelayanan Intensive
Care Unit (ICU) di Ruma Sakit. Jakarta : Kementrian Kesehatan RI (http://www.depkes.go.id/download.p hp?file=d ownload/ -SIK-2016.pdf.) diakses 2 Agustus 2019.

Kiptiyah. (2013). Gambaran Tingkat Kecemasan Keluarga Pasien di Ruang ICU Rumah Sakit Umum Daerah Cibinong.

http://www.lib.ui.ac.id/unggah/?q=skripsi 12053. Di unduh pada tanggal 12 Agustus 2019

Mirwanti R dan Nuraeni A. (2016). Hubungan Kesejahteraan Spiritual Dengan Depresi Pada Pasien Dengan Penyakit Jantun Koroner. Jurnal Ilmu-ilmu Kesehatan Vol 14 (1) 2016

Nawawi, R.A.S. (2011). Keribadian Qur'ani. Jakarta: Amzah.

Networks H. (2006). Living On The Outside. Chiang Mai: health and Development Networks.

Pieter, H.Z., dan Lubis, N.L. (2011). Pengantar Psikopatologi untuk Keperawatan. Jakarta: Kencana Pren ada Media Group.

Suprihatiningsih T, Dewi S. dan Pranowo S. (2019). Pengaruh Bereavement Life Review terhadap Depresi dan Kesejahteraan Spiritual Keluarga Pasien Kemoterapi. Jurnal Kesehatan Al Irsyad, XII (2).

Yosep, I. (2014). Keperawatan Jiwa. Bandung: PT Rafika Aditama.

Yusuf, A., Nihayati, H.E., dan Iswari, M.F. (2016). Kebutuhan Spiritual; Konsep dan Aplikasi Dalam Asuhan keperawatan. Jakarta: Mitra Wacana Media 